\title{
Efeito do conteúdo de água e da compactação do solo na produção de soja(1)
}

\author{
Amauri Nelson Beutler(2) e José Frederico Centurion(2)
}

\begin{abstract}
Resumo - A compactação do solo tem sido fator físico limitante ao crescimento das plantas. Este trabalho objetivou avaliar a produção de soja (Glycine max cv. EMBRAPA 48) em razão do conteúdo de água e da compactação do solo. Usou-se o delineamento inteiramente casualizado, em esquema fatorial 4x2, ou seja, quatro níveis de resistência à penetração (entre 0,27 e 4,32 MPa) e dois níveis de retenção de água pelo solo $(0,05$ e 0,01 MPa). Foram utilizadas amostras de Latossolo Vermelho textura média (LVd) e Latossolo Vermelho textura argilosa (LVef), coletadas na profundidade de $0-20 \mathrm{~cm}$, passadas em peneira de $0,4 \mathrm{~cm}$ e compactadas em camadas de $3 \mathrm{~cm}$, em vasos de $20 \mathrm{~cm}$ de altura e $25 \mathrm{~cm}$ de diâmetro $(9,82 \mathrm{~L})$. Os níveis de resistência à penetração foram determinados com o penetrômetro de anel dinamométrico. O nível crítico de resistência do solo à penetração, em relação à produção de grãos, foi de 1,66 e 2,22 MPa, no LVd, e 3,05 e 2,81 MPa, no LVef, para o conteúdo de água retida na tensão de 0,05 e $0,01 \mathrm{MPa}$, respectivamente. A maior produção de grãos foi obtida na tensão de 0,01 MPa. A produção de grãos de soja é afetada em níveis críticos de resistência do solo à penetração superiores a $2 \mathrm{MPa}$ em latossolos com conteúdo de água retida na tensão de $0,01 \mathrm{MPa}$.
\end{abstract}

Termos para indexação: Glycine max, resistência do solo, umidade do solo, densidade do solo, manejo do solo.

\section{Effect of water content and soil compaction in soybean production}

\begin{abstract}
Soil compaction has been limiting physical factor to plants growth. This work aimed to evaluate the production of soybean (Glycine max cv. EMBRAPA 48) as affected by water content and soil compaction. The experimental design was completely randomized, in a factorial scheme $4 \times 2$, i.e., four levels of resistance to penetration (between 0.27 and $4.32 \mathrm{MPa}$ ) and two levels of soil water retention $(0.05$ and $0.01 \mathrm{MPa})$. Samples of Red Latossol medium texture and Red Latossol clayey were collected in $0-20 \mathrm{~cm}$ depth, sieved in mesh of $0.4 \mathrm{~cm}$ and compacted in layers of $3 \mathrm{~cm}$ in pots of $20 \mathrm{~cm}$ height and $25 \mathrm{~cm}$ of diameter $(9.82 \mathrm{~L})$. The levels of resistance to penetration were determined with dynamometric ring penetrometer. The critical level of soil resistance to penetration, in relation to grains production, was 1.66 and $2.22 \mathrm{MPa}$, in Red Latossol medium texture, and 3.05 and $2.81 \mathrm{MPa}$, in Red Latossol clayey, for the water content in tension of 0.05 and $0.01 \mathrm{MPa}$, respectively. The higher grains production was obtained in tension of $0.01 \mathrm{MPa}$. Soybean production is affected by levels of soil resistance to penetration superior to $2 \mathrm{MPa}$ in latossols under tension of $0.01 \mathrm{MPa}$.
\end{abstract}

Index terms: Glycine max, soil strength, soil moisture, soil density, soil management.

\section{Introdução}

A principal cultura de grãos do país é a da soja, a qual abrange uma área de 15,5 milhões de hectares (Agrianual, 2001). O incremento da produção dessa leguminosa está ocorrendo menos pelo

(1) Aceito para publicação em 29 de abril de 2003. Projeto financiado pela Fapesp.

(2)Universidade Estadual Paulista, Faculdade de Ciências Agrárias e Veterinárias, Dep. de Solos e Adubos, Via de Acesso Rod. Paulo Donato Castellane, s/no, CEP 14870-000 Jaboticabal, SP. E-mail: amaurib@yahoo.com.br, jfcentur@fcav.unesp.br desmatamento de extensas áreas para seu cultivo do que pelo aumento da produtividade, proporcionado pelo manejo racional dos solos e dos insumos agrícolas (Agrianual, 2001). Neste contexto, a compactação do solo assume importância relevante nas relações físicas, químicas e biológicas do solo, que afetam o crescimento das plantas.

Por estar diretamente relacionada ao crescimento das plantas, a resistência do solo à penetração tem sido o atributo físico priorizado em trabalhos que estudam a compactação do solo (Weaich et al., 1992; Imhoff et al., 2000). A resistência à penetração apresenta forte relação com o crescimento radical das 
plantas (Bengough \& Mullins, 1990; Smith et al., 1997; Hoad et al., 2001). É muito influenciada pelo teor de umidade e pela condição estrutural do solo, o que dificulta a obtenção de valores limitantes em relação à produção das culturas (Hamblim, 1985; Tardieu, 1994; Unger \& Kaspar, 1994).

Valores críticos de resistência à penetração variam de 1,5 a 4,0 MPa (Nesmith, 1987; Topp et al., 1994; Arshad et al., 1996; Tormena et al., 1998; Imhoff et al., 2000), sendo, em geral, o valor de $2 \mathrm{MPa}$ aceito como impeditivo ao crescimento radical (Tormena et al., 1998). Em Latossolo Roxo, Mielniczuk et al. (1985) verificaram, em vasos, menor crescimento da parte aérea de soja em resposta à resistência de 3,03 MPa, e Petter (1990), no campo, verificou, em Latossolo, menor crescimento radical de soja a partir de 2,8 $\mathrm{MPa}$.

As plantas apresentam diferentes respostas à resistência do solo à penetração, variando entre culturas e cultivares (Mielniczuk et al., 1985). As raízes das plantas que crescem em solos com alta resistência à penetração apresentam modificações morfológicas. Assim, decréscimo na divisão celular no meristema e aumento no diâmetro da raiz, resultante do aumento na espessura do córtex, reduzem a área de solo explorado pelas raízes e a absorção de água e nutrientes (Taylor \& Brar, 1991; Bengough et al., 1997). Segundo esses autores, em condições adversas ao crescimento, as raízes enviam sinais à parte aérea informando que as condições para o desenvolvimento da planta estão se restringindo e que é necessário reduzir a taxa de crescimento, resultando em menor produção.

Por sua vez, foi verificado que solos excessivamente porosos são prejudiciais à absorção de água e nutrientes pelas raízes, por causa do menor contato solo/raiz, provocando também menor desenvolvimento das plantas (Kooistra et al., 1992; Hakansson et al., 1998).

A maioria dos estudos com níveis críticos de resistência à penetração avaliam camadas subsuperficiais de solo compactado. Entretanto, segundo Johnson et al. (1990), em camadas superficiais compactadas a produção de soja foi menor em $15 \%$ em relação a solos compactados na subsuperfície, em que apenas ocorreu redução na altura de plantas. Com o aumento gradativo das áreas cultivadas em sistemas com menor revolvimento, denominado plantio direto, tem sido verificada a compactação superficial do solo, mas poucos são os estudos sobre os níveis críticos de resistência à penetração para produção de grãos de soja. Imhoff et al. (2000), estudando a curva de resistência do solo em relação à umidade e densidade do solo, considerou que o nível crítico de resistência à penetração, em solo sob pastagens, era de 2,5 $\mathrm{MPa}$.

Este trabalho objetivou avaliar a produção de soja em razão do conteúdo de água e da compactação do solo.

\section{Material e Métodos}

O experimento foi realizado em 2001 em casa de vegetação do Departamento de Solos e Adubos da FCAV/ Unesp de Jaboticabal, SP, em Latossolo Vermelho distrófico típico textura média A moderado caulinítico hipoférrico (LVd) e Latossolo Vermelho eutroférrico típico textura argilosa A moderado caulinítico-oxídico (LVef). A composição granulométrica foi determinada em amostras deformadas mediante dispersão com $\mathrm{NaOH}$ $\left(0,1 \mathrm{~mol} \mathrm{~L}^{-1}\right)$ e agitação lenta durante 16 horas, e o conteúdo de argila obtido pelo método da pipeta (Day, 1965). Os solos LVd e LVef apresentaram, respectivamente, 271 e $517 \mathrm{~g} \mathrm{~kg}^{-1}$ de argila, 42 e $256 \mathrm{~g} \mathrm{~kg}^{-1}$ de silte e 687 e $227 \mathrm{~g} \mathrm{~kg}^{-1}$ de areia; a densidade de partículas foi de $2,82 \mathrm{e}$ $2,98 \mathrm{Mg} \mathrm{m}^{-3}$

As amostras dos solos foram coletadas na camada de 0-20 cm e passadas em peneira de $0,4 \mathrm{~cm}$. Os solos foram adubados segundo Raij et al. (1996); em $1 \mathrm{~m}^{3}$ de solo foi utilizada a adubação referente a $5 \mathrm{~m}^{2}$ no campo, cuja análise química foi realizada conforme Raij et al. (1987). A caracterização química do solo antes e após a adubação e no momento da colheita é apresentada na Tabela 1.

Após a adubação, foram ajustados os conteúdos de água de 0,11 e $0,14 \mathrm{~kg} \mathrm{~kg}^{-1}$ no LVd e 0,24 e $0,27 \mathrm{~kg} \mathrm{~kg}^{-1}$ no LVef, correspondentes aos conteúdos de água retida nas tensões de 0,05 e $0,01 \mathrm{MPa}$, respectivamente, os quais foram determinados previamente em câmaras de Richards, em amostras indeformadas (Klute, 1986). Em seguida, o solo foi colocado em vaso cilíndrico de PVC com capacidade de 9,82 L ( $20 \mathrm{~cm}$ de altura e $25 \mathrm{~cm}$ de diâmetro), em camadas de $3 \mathrm{~cm}$. Cada camada foi compactada por meio da queda livre de um êmbolo de $7 \mathrm{~kg}$, da altura de $60 \mathrm{~cm}$, no centro geométrico de uma superfície de madeira com diâmetro ligeiramente inferior ao do vaso, semelhante ao descrito por Moraes et al. (1991). Foram estabelecidos quatro níveis de resistência do solo à penetração. 
A resistência à penetração foi determinada com o penetrômetro de anel dinamométrico (Solotest 1.210.001), com ângulo de cone de $30^{\circ}$. As leituras foram realizadas quando a base do cone atingiu a profundidade de $3 \mathrm{~cm}$ a partir da superfície do solo, e o valor de cada repetição foi obtido da média de quatro subdeterminações. Foram utilizados cones com área de 6,33, 3,8, 1,13 e $0,28 \mathrm{~cm}^{2}$, diminuindo a área do cone com o incremento da compactação do solo.

Foram semeadas três sementes de soja cultivar EMBRAPA 48 por cova, sendo quatro covas por vaso. Após sete dias, realizou-se o desbaste, deixando duas plantas de soja por vaso. Nessa data foram aplicados os tratamentos de umidade do solo para possibilitar a germinação nos vasos mais secos e compactados. A umidade foi mantida constante, após duas pesagens diárias dos vasos referentes a uma repetição e reposição de água por meio de tubo de PVC perfurado, instalado no centro geométrico do vaso; a pesagem e o rodízio dos vasos foram feitos a cada cinco dias.

Foram avaliados a altura das plantas, altura da inserção da primeira vagem, vagens/planta, grãos/vagem, grãos/ planta, peso de 100 sementes, produção de grãos/planta, de matéria seca da parte aérea e das raízes. A umidade dos grãos foi ajustada a $0,12 \mathrm{~kg} \mathrm{~kg}^{-1}$.

Os tratamentos consistiram de quatro níveis de resistência à penetração e dois níveis de umidade, constituindo um experimento inteiramente casualizado, em esquema fatorial $4 \times 2$, com três repetições, de cada solo. Foram realizadas análises de variância, comparação de médias pelo teste de Tukey a 5\% de probabilidade e regressão entre a resistência à penetração e produção de matéria seca da parte aérea, das raízes e de grãos. A análise estatística do número de vagens/planta, grãos/vagem e grãos/planta foi realizada com os dados transformados em $\sqrt{\mathrm{x}}$. As análises foram processadas por meio do Statistical Analysis System (SAS Institute, 1996).

\section{Resultados e Discussão}

A altura das plantas, o número de vagens e grãos por planta foram, em geral, superiores nos dois solos, na tensão de 0,01 MPa (Tabela 2). A altura das plantas e a distância do solo até a inserção da primeira vagem, características importantes quando a colheita é realizada mecanicamente, foram pouco alteradas entre os níveis de resistência do solo à penetração. Já o número de vagens por planta foi menor, no $\mathrm{LVd}$, na resistência à penetração de 4,18 e $3,58 \mathrm{MPa}$, na tensão de 0,05 e 0,01 MPa, respectivamente, e no LVef foi menor a partir de 2,54 MPa, na tensão de 0,01 MPa.

A produção de matéria seca da parte aérea, das raízes e de grãos foi maior na tensão de 0,01 $\mathrm{MPa}$, comparado a 0,05 $\mathrm{MPa}$ (Figuras 1 e 2). Tardieu (1994) e Unger \& Kaspar (1994) também verificaram que num mesmo nível de resistência à penetração os efeitos da resistência são menos pronunciados quando há maior conteúdo de água.

Segundo Novais \& Smyth (1999), em maior conteúdo de água, além da maior disponibilidade de água no solo, o filme de água das partículas sólidas fica mais espesso, diminuindo a interação íon-colóide e aumentando a quantidade de nutrientes na solução do solo; também ocorre maior difusão dos nutrientes no solo, como o P, que, segundo Fernandez et al.

Tabela 1. Caracterização química do Latossolo Vermelho distrófico (LVd) e do Latossolo Vermelho eutroférrico (LVef) utilizado para o cultivo de soja, antes e após a realização da adubação, e na colheita.

\begin{tabular}{|c|c|c|c|c|c|c|c|}
\hline Solo & $\mathrm{pH}\left(\mathrm{CaCl}_{2}\right)$ & $\begin{array}{c}\mathrm{MO} \\
\left(\mathrm{g} \mathrm{dm}^{-3}\right)\end{array}$ & $\begin{array}{c}\mathrm{P}_{\text {resina }} \\
\left(\mathrm{mg} \mathrm{dm}^{-3}\right)\end{array}$ & $\mathrm{K}$ & $\begin{array}{l}\mathrm{Ca} \\
\mathrm{l}_{\mathrm{c}} \mathrm{dm}\end{array}$ & $\mathrm{Mg}$ & $\begin{array}{c}\mathrm{V} \\
(\%)\end{array}$ \\
\hline \multicolumn{8}{|c|}{ Antes da adubação } \\
\hline LVd & 5,2 & 14 & 18 & 1,2 & 14 & 10 & 52 \\
\hline LVef & 4,8 & 37 & 16 & 1,2 & 21 & 10 & 41 \\
\hline \multicolumn{8}{|c|}{ Após a adubação } \\
\hline LVd & 5,5 & 11 & 27 & 2,5 & 16 & 13 & 64 \\
\hline LVef & 5,5 & 42 & 80 & 4,8 & 55 & 25 & 71 \\
\hline \multicolumn{8}{|c|}{ Após a colheita ${ }^{(1)}$} \\
\hline LVd & 6,0 & 10 & 22 & 2,1 & 20 & 11 & 67 \\
\hline LVef & 5,7 & 37 & 56 & 2,5 & 55 & 17 & 71 \\
\hline
\end{tabular}

${ }^{(1)}$ Os nutrientes no solo após a colheita estavam no nível médio a alto de acordo com Raij et al. (1996). 
(1995), é o nutriente mais limitante em oxissolos.

A menor produção no menor nível de resistência à penetração ocorreu com solo solto, apesar de in situ o sistema radical estar distribuído em todo o solo do vaso (Figuras 1 e 2). Hakansson et al. (1998) verificaram que solos excessivamente soltos apresentam menores produções por causa do menor contato solo/raiz, que diminui a habilidade do sistema radical em absorver quantidades adequadas de água e nutrientes.

As menores produções foram obtidas no solo mantido extremamente solto durante o ciclo da cultura. Esta condição física no campo se desfaz após as primeiras chuvas depois do preparo do solo, quando ocorre o rearranjamento das partículas de solo e aumento da densidade. Assim, foi enfatizado o ní- vel a partir do qual ocorre redução da produção de grãos de soja, denominado nível crítico.

Houve maior redução da produção de matéria seca das raízes nos menores níveis de resistência à penetração em relação à redução da produção de matéria seca da parte aérea, que foi próxima à redução da produção de grãos (Figuras 1 e 2). Assim, fica demonstrado que inicialmente ocorre redução da produção da matéria seca das raízes mas não necessariamente da produção da matéria seca da parte aérea e de grãos. Taylor \& Brar (1991) também constataram que muitas vezes ocorrem mudanças e redução no comprimento das raízes, porém estas mantêm satisfatoriamente o suprimento de água e nutrientes para a parte aérea, não refletindo em menor produção.

Tabela 2. Componentes de desenvolvimento de soja em razão de níveis de resistência do solo à penetração e de conteúdos de água retida nas tensões de $0,05 \mathrm{MPa}\left(0,11 \mathrm{~kg} \mathrm{~kg}^{-1}\right)$ e $0,01 \mathrm{MPa}\left(0,14 \mathrm{~kg} \mathrm{~kg}^{-1}\right)$ no Latossolo Vermelho distrófico (LVd) e de 0,05 MPa $\left(0,24 \mathrm{~kg} \mathrm{~kg}^{-1}\right)$ e 0,01 MPa $\left(0,27 \mathrm{~kg} \mathrm{~kg}^{-1}\right)$ no Latossolo Vermelho eutroférrico (LVef)(1).

\begin{tabular}{|c|c|c|c|c|c|c|}
\hline $\begin{array}{l}\text { Resistência à } \\
\text { penetração } \\
\text { (MPa) }\end{array}$ & $\begin{array}{l}\text { Altura da } \\
\text { planta }\end{array}$ & $\begin{array}{l}\text { Altura da } \\
\text { vagem }^{(2)}\end{array}$ & $\begin{array}{l}\text { Vagens/ } \\
\text { planta }\end{array}$ & $\begin{array}{l}\text { Grãos/ } \\
\text { vagem } \\
--\left(n^{\underline{o}}\right)-\end{array}$ & $\begin{array}{l}\text { Grãos/ } \\
\text { planta }\end{array}$ & $\begin{array}{l}\text { Peso de } 100 \\
\text { sementes } \\
(\mathrm{g})\end{array}$ \\
\hline \multicolumn{6}{|c|}{$\mathrm{LVd}$} & \\
\hline 0,27 & $50,83 \mathrm{Aa}$ & 9,92Aa & $19,50 \mathrm{Ab}$ & 2,07Aa & $40,33 \mathrm{Ab}$ & $13,38 \mathrm{Bb}$ \\
\hline 2,04 & $37,00 \mathrm{ABb}$ & $8,08 \mathrm{Aa}$ & $23,17 \mathrm{Ab}$ & $1,86 \mathrm{Aa}$ & $43,00 \mathrm{Ab}$ & $13,36 \mathrm{Ba}$ \\
\hline 2,75 & $35,33 \mathrm{ABb}$ & 7,57Aa & $23,17 \mathrm{Ab}$ & $1,84 \mathrm{Aa}$ & $42,67 \mathrm{Ab}$ & $13,46 \mathrm{Bb}$ \\
\hline 4,18 & $31,00 \mathrm{Bb}$ & $10,83 \mathrm{Aa}$ & $10,83 \mathrm{Bb}$ & $1,80 \mathrm{Aa}$ & $19,33 \mathrm{Bb}$ & $16,70 \mathrm{Aa}$ \\
\hline \multicolumn{7}{|c|}{ Tensão de $0,01 \mathrm{MPa}$} \\
\hline 0,31 & $56,33 \mathrm{Aa}$ & 9,50Aa & $31,50 \mathrm{Ca}$ & 1,89Aa & $59,67 \mathrm{Ca}$ & $14,79 \mathrm{Aa}$ \\
\hline 1,79 & $55,17 \mathrm{Aa}$ & $8,83 \mathrm{Aa}$ & $51,33 \mathrm{Aa}$ & 1,91Aa & $98,33 \mathrm{Aa}$ & $13,87 \mathrm{Aa}$ \\
\hline 2,32 & $52,83 \mathrm{Aa}$ & 9,58Aa & $46,83 \mathrm{Aa}$ & 1,93Aa & $90,50 \mathrm{Aa}$ & $14,89 \mathrm{Aa}$ \\
\hline 3,58 & $52,50 \mathrm{Aa}$ & $8,33 \mathrm{Aa}$ & $38,00 \mathrm{Ba}$ & $1,98 \mathrm{Aa}$ & $75,17 \mathrm{Ba}$ & $15,01 \mathrm{Ab}$ \\
\hline $\mathrm{CV}(\%)$ & 18,12 & 19,27 & 3,36 & 2,76 & 3,53 & 7,32 \\
\hline \multicolumn{7}{|c|}{$\begin{array}{c}\text { LVef } \\
\text { ão de } 0,0\end{array}$} \\
\hline 0,43 & $42,33 \mathrm{Ab}$ & $10,17 \mathrm{Aa}$ & $12,83 \mathrm{Bb}$ & $1,95 \mathrm{Aa}$ & $24,83 \mathrm{Cb}$ & $14,51 \mathrm{Aa}$ \\
\hline 2,52 & $55,50 \mathrm{Aa}$ & $9,63 \mathrm{Aa}$ & $37,83 \mathrm{Ab}$ & 1,94Aa & $73,67 \mathrm{Ab}$ & $16,32 \mathrm{Aa}$ \\
\hline 3,83 & $52,33 \mathrm{Aa}$ & $8,33 \mathrm{Aa}$ & $37,00 \mathrm{Ab}$ & 1,89Aa & $70,00 \mathrm{ABb}$ & $16,05 \mathrm{Aa}$ \\
\hline 4,32 & $51,42 \mathrm{Aa}$ & $8,83 \mathrm{Aa}$ & $32,33 \mathrm{Ab}$ & $1,90 \mathrm{Aa}$ & $61,33 \mathrm{Bb}$ & $17,01 \mathrm{Aa}$ \\
\hline \multicolumn{7}{|c|}{ Tensão de $0,01 \mathrm{MPa}$} \\
\hline 0,27 & $61,17 \mathrm{Aa}$ & $9,58 \mathrm{Aa}$ & $32,50 \mathrm{Ca}$ & 1,89Aa & $61,50 \mathrm{Ba}$ & $15,05 \mathrm{Aa}$ \\
\hline 1,78 & $64,83 \mathrm{Aa}$ & $9,08 \mathrm{Aa}$ & $64,33 \mathrm{Aa}$ & 1,88Aa & $120,67 \mathrm{Aa}$ & $15,51 \mathrm{Aa}$ \\
\hline 2,54 & $59,17 \mathrm{Aa}$ & $8,17 \mathrm{Aa}$ & $60,67 \mathrm{Ba}$ & 1,91Aa & $115,67 \mathrm{Aa}$ & $15,20 \mathrm{Aa}$ \\
\hline 4,03 & $56,83 \mathrm{Aa}$ & $8,08 \mathrm{Aa}$ & $59,83 \mathrm{Ba}$ & $1,92 \mathrm{Aa}$ & $114,83 \mathrm{Aa}$ & $14,69 \mathrm{Ab}$ \\
\hline $\mathrm{CV}(\%)$ & 12,2 & 11,95 & 3,79 & 4,02 & 4,61 & 5,3 \\
\hline
\end{tabular}

(1)Médias, na coluna, seguidas pela mesma letra maiúscula na mesma tensão e minúscula entre tensões, não diferem entre si a 5\% de probabilidade pelo teste de Tukey. ${ }^{(2)}$ Distância do solo até a inserção da primeira vagem. 

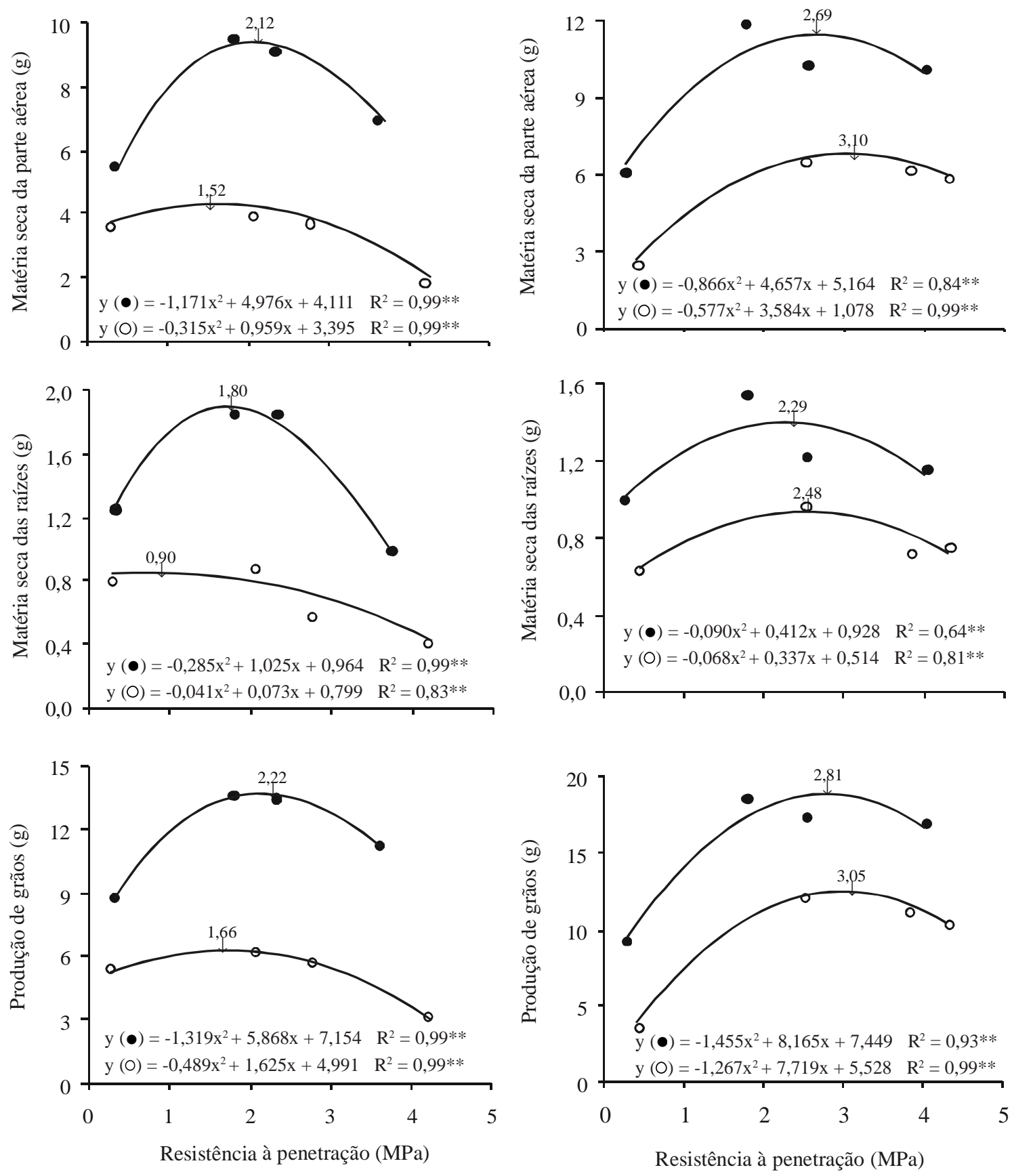

Figura 1. Produção de matéria seca da parte aérea e das raízes e produção de grãos/planta, no Latossolo Vermelho distrófico (LVd), em diferentes níveis de resistência do solo à penetração e no conteúdo de água $\left(0,11 \mathrm{~kg} \mathrm{~kg}^{-1}\right)$ retida na tensão de $0,05 \mathrm{MPa}$ (o) e conteúdo de água $\left(0,14 \mathrm{~kg} \mathrm{~kg}^{-1}\right)$ retida na tensão de $0,01 \mathrm{MPa}(\bullet)$.

Figura 2. Produção de matéria seca da parte aérea e das raízes e produção de grãos/planta, no Latossolo Vermelho eutroférrico (LVef), em diferentes níveis de resistência do solo à penetração e no conteúdo de água $\left(0,24 \mathrm{~kg} \mathrm{~kg}^{-1}\right)$ retida na tensão de $0,05 \mathrm{MPa}$ (o) e conteúdo de água $\left(0,27 \mathrm{~kg} \mathrm{~kg}^{-1}\right)$ retida na tensão de $0,01 \mathrm{MPa}(\bullet)$. 
Entretanto, a excessiva redução da matéria seca do sistema radical, por causa da alta resistência do solo à penetração, resultou em menor produção de matéria seca da parte aérea e de grãos (Figuras 1 e 2). In situ ocorreu decréscimo gradual do sistema radical das plantas com o incremento da resistência à penetração; no vaso com solo solto observou-se grande número de raízes distribuídas em todo o vaso, e no solo compactado, as raízes mais finas se concentram na camada superficial de $5 \mathrm{~cm}$ e poucas raízes espessas cresceram em profundidade.

Isto ocorreu, segundo Hoad et al. (2001), por causa do menor comprimento e maior espessura das raízes, que diminuem a área de contato solo/raiz e, ainda, por essas raízes possuírem menor resistência de transporte no xilema em relação às raízes mais finas. Assim, diminui a absorção de nutrientes por causa da baixa taxa de difusão de alguns nutrientes, como o P, que é crucial ao desenvolvimento radical e que é aproveitado apenas quando se encontra até a $1 \mathrm{~mm}$ da raiz (Hoad et al., 2001). De fato, Borges et al. (1988) verificaram sintomas de deficiência de $\mathrm{P}$ e $\mathrm{K}$ nas folhas de soja à medida que a compactação aumentou.

Outro aspecto são os valores próximos de resistência à penetração em que ocorreu redução da produção da matéria seca da parte aérea em relação à produção de grãos, nos dois solos, indicando que a redução da matéria seca da parte aérea interferiu diretamente na produção de grãos de soja.

Houve redução na produção de grãos a partir do segundo e terceiro nível de resistência à penetração (Figuras 1 e 2), e o teor de nutrientes no solo, após a colheita, foi semelhante entre os níveis de resistência à penetração (Tabela 1). Possivelmente, a quantidade diferenciada de nutrientes absorvidos pelas plantas não foi verificada pela análise química por causa do grande volume de solo $(9,82 \mathrm{~L})$.

No LVd, o limite crítico de resistência à penetração em relação à produção de grãos foi de 1,66 e 2,22 $\mathrm{MPa}$, e da matéria seca das raízes foi de 0,90 e $1,80 \mathrm{MPa}$, nas tensões de 0,05 e 0,01 MPa, respectivamente (Figura 1). Esses níveis são inferiores aos aceitos como impeditivos ao crescimento radical de $2 \mathrm{MPa}$ (Tormena et al., 1998). Entretanto, a redução da produção é muito pequena quando considerado o nível de 2,22 $\mathrm{MPa}$ em vez de 1,66 MPa na tensão de 0,05 MPa, sendo a umidade do solo mais importante na produção. Desta forma, pode ser adotado o valor de $2,22 \mathrm{MPa}$ como crítico para a produção da soja nesse solo.

No LVef, foram obtidas maiores produções em relação ao LVd (Figura 2), condizente com os maiores teores de P, K, Ca e Mg no solo (Tabela 1), corroborando os estudos de Tu \& Tan (1991) que atribuíram a maior produção das plantas em solo argiloso, no mesmo nível de compactação, ao maior teor de nutrientes e matéria orgânica em relação ao solo arenoso.

Os níveis críticos de resistência à penetração, no LVef, em relação à produção de grãos foi de 3,05 e 2,81 $\mathrm{MPa}$, e da matéria seca da parte aérea foi 3,10 e 2,69 MPa, nas tensões de 0,05 e 0,01 MPa, respectivamente (Figura 2). Mielniczuk et al. (1985) também verificaram que a produção de matéria seca da parte aérea de soja foi menor em 3,03 MPa, em Latossolo Roxo com $0,28 \mathrm{~kg} \mathrm{~kg}^{-1}$ de água.

No LVef, as plantas de soja suportaram maiores níveis de resistência à penetração em relação ao $\mathrm{LVd}$, indicando a importância da estrutura do solo, conforme mencionado por Hamblim (1985). Os maiores valores críticos de resistência à penetração em relação à produção de grãos, no LVef, devem-se à maior porosidade deste solo, conforme verificado por Beutler et al. (2002). Por sua vez, a maior porosidade deve-se à mineralogia oxídica deste solo que condiciona uma estrutura maciça porosa in situ (Ferreira et al., 1999). Assim, quando há maior resistência à penetração, ocorre maior contato solo/ raiz, o que favorece a absorção de água e nutrientes por unidade de raiz (Hakansson et al., 1998) no LVef em relação ao LVd, este com mineralogia caulinítica com aspecto maciço coeso e menos poroso.

\section{Conclusão}

O nível crítico de resistência do solo à penetração para a produção de grãos de soja é superior a $2 \mathrm{MPa}$ em latossolos com água retida na tensão de $0,01 \mathrm{MPa}$.

\section{Referências}

AGRIANUAL 2002: anuário da agricultura brasileira. São Paulo: FNP Consultoria e Comércio, 2001. 536 p. 
ARSHAD, M. A.; LOWERY, B.; GROSSMAN, B Physical tests for monitoring soil quality. In: DORAN, J. W.; JONES, A. J. Methods for assessing soil quality. Madison: Soil Science Society of America, 1996. p. 123141. (SSSA Special Publication, 49).

BENGOUGH, A. G.; CROSER, C.; PRITCHARD, J. A biophysical analysis of root growth under mechanical stress. Plant and Soil, Dordrecht, v. 189, p. 155-164, 1997.

BENGOUGH, A. G.; MULlins, C. E. Mechanical impedance to root growth: a review of experimental techniques and root growth responses. Journal of Soil Science, Oxford, v. 41, p. 341-358, 1990.

BEUTLER, A. N.; CENTURION, J. F.; SOUZA, Z. M.; SILVA, L. M. Utilização dos penetrômetros de impacto e de anel dinamométrico em Latossolos. Engenharia Agrícola, Jaboticabal, v. 22, p. 191-199, 2002.

BORGES, E. N.; NOVAIS, R. F.; REGAZZI, A. J.; FERNANDES, B.; BARROS, N. F. Respostas de variedades de soja à compactação do solo. Revista Ceres, Viçosa, MG, v. 35, p. 553-568, 1988.

DAY, P. R. Particle fractionation and particle size analyses. In: AMERICAN SOCIETY OF AGRONOMY (Madison, Estados Unidos). Methods of soil analysis. Madison, 1965. p. 545-566.

FERNANDEZ, E. M.; CRUSCIOL, C. A. C.; THIMOTEO, C. M. de S.; ROSOLEM, C. A. Matéria seca e nutrição da soja em razão da compactação do solo e adubação fosfatada. Científica, São Paulo, v. 23, p. 117 132, 1995.

FERREIRA, M. M.; FERNANDES, B.; CURI, N. Mineralogia da fração argila e estrutura de latossolos da Região Sudeste do Brasil. Revista Brasileira de Ciência do Solo, Viçosa, MG, v. 23, p. 507-514, 1999.

HAKANSSON, I.; STENBERG, M.; RYDBERG, T. Long term experiments with different depths of mouldboard plough in Sweden. Soil and Tillage Research, Amsterdam, v. 46, p. 209-223, 1998.

HAMBLIM, A. P. The influence of soil structure on water movement, crop root growth and water uptake. Advances in Agronomy, New York, v. 38, p. 95-158, 1985.

HOAD, S. P.; RUSSEL, G.; LUCAS, M. E.; BINGHAM, I. J. The management of wheat, barley, and oat root systems. Advances in Agronomy, New York, v. 74, p. 195254, 2001
IMHOFF, S.; SILVA, A. P.; TORMENA, C. A. Aplicações da curva de resistência no controle da qualidade física de um solo sob pastagem. Pesquisa Agropecuária Brasileira, Brasília, v. 35, n. 7, p. 1493-1500, jul. 2000.

JOHNSON, J. F.; VOORHEES, W. B.; NELSON, W. W.; RANDALL, G. W. Soybean growth and yield as affected by surface and subsoil compaction. Agronomy Journal, Madison, v. 82, p. 973-979, 1990.

KLUTE, A. Water retention: laboratory methods. In: KLUTE, A. (Ed.). Methods of soil analysis. $2^{\text {nd }}$ ed. Madison: American Society of Agronomy, 1986. pt. 1, p. 635-662.

KOOISTRA, M. J.; SCHOONDERBEEK, D.; BOONE, F. R.; VEEN, B. W.; NOORDWIJK, M. van. Root soil contact of maize, as measured by a thin section technique II: effects of soil compaction. Plant and Soil, Dordrecht, v. 139, p. 119-129, 1992.

MIELNICZUK, J.; CARPENEDO, V.; PEDO, F. Desenvolvimento de raízes em solos compactados. Lavoura Arrozeira, Porto Alegre, v. 38, p. 42-43, 1985.

MORAES, M. H.; BENEZ, S. H.; LIBARDI, P. L. Influência de camadas compactadas de subsuperfície no desenvolvimento do sistema radicular de plantas de soja (Glycine $\max$ (L.) Merrill). Científica, São Paulo, v. 19, p. 195-206, 1991.

NESMITH, D. S. Soil compaction in double cropped wheat and soyabean on Ultissol. Soil Science Society of America Journal, Madison, v. 51, p. 183-186, 1987.

NOVAIS, R. F.; SMYTH, T. J. Fósforo em solo e planta em condições tropicais. Viçosa, MG: UFV, 1999. 399 p.

PETTER, R. L. Desenvolvimento radicular da soja em função da compactação do solo, conteúdo de água e fertilidade em Latossolo. 1990. 144 f. Dissertação (Mestrado em Biodinâmica do Solo) - Universidade Federal de Santa Maria, Santa Maria, 1990.

RAIJ, B. van; CANTARELLA, H.; QUAGGIO, J. H.; FURLANI, A. M. C. Recomendação de adubação e calagem para o Estado de São Paulo. 2. ed. Campinas: Instituto Agronômico, 1996. 285 p. (Boletim Técnico, 100).

RAIJ, B. van; QUAGGIO, J. A.; CANTARELLA, H.; FERREIRA, M. E.; LOPES, A. S.; BATAGLIA, O. C. Análise química do solo para fins de fertilidade. Campinas: Fundação Cargill, 1987. 170 p.

Pesq. agropec. bras., Brasília, v. 38, n. 7, p. 849-856, jul. 2003 
SAS INSTITUTE (Cary, Estados Unidos). SAS/STAT procedure guide for personal computers. $5^{\text {th }}$ ed. Cary, 1996. $1686 \mathrm{p}$.

SMITH, C. W.; JOHNSTON, M. A.; LORENTZ, S. The effect of soil compaction and soil physical properties on the mechanical resistance of South African forestry soils. Geoderma, Amsterdam, v. 78, p. 93-111, 1997.

TARDIEU, F. Growth and functioning of roots and to root systems subjected to soil compaction: towards a system with multiple signaling. Soil and Tillage Research, Amsterdam, v. 30, p. 217-243, 1994.

TAYLOR, H. M.; BRAR, G. S. Effect of soil compaction on root development. Soil and Tillage Research, Amsterdam, v. 19, p. 111-119, 1991.

TOPP, G. C.; GALGANOW, Y. T.; WIRES, K. C. Non limiting water range (NLWR): an approach for assessing soil structure. Ottawa: Soil Quality Evaluation Program, 1994. 96 p. (Technical Report, 2).

TORMENA, C. A.; SILVA, A. P. da; LIBARDI, P. L. Caracterização do intervalo hídrico ótimo de um Latossolo Roxo sob plantio direto. Revista Brasileira de Ciência do Solo, Campinas, v. 22, p. 573-581, 1998

TU, J. C.; TAN, C. S. Effect of soil compaction on growth, yield and root rots of white beans in clay loam and sandy loam soil. Soil Biology and Biochemistry, Oxford, v. 23, n. 3, p. 233-238, 1991.

UNGER, W. P.; KASPAR, T. C. Soil compaction and root growth: a review. Agronomy Journal, Madison, v. 86, p. 759-766, 1994

WEAICH, K.; BRISTOW, K. L.; CASS, A. Preemergent shoot growth of maize under different drying conditions. Soil Science Society of America Journal, Madison, v. 56, p. 1272-1278, 1992 